\title{
No Easy Task
}

\section{Dear Reader,}

The 2020 ATZlive Conference on Autonomous Driving is all set to take place from October 13 to 14, 2020. The year 2020 introduces a special opportunity for smaller, more intimate events. After much deliberation, big ones such as the SPS were cancelled; the Electronica has met the same fate. And, of course, it has long been established that the CES 2021 "will be an all-digital experience." Smaller specialist events, however, have the option to allow physical presence of the participants. And that is a good thing.

Providing venues for experts to discuss and identify promising paths forward in the area of autonomous driving seeems to be key to make any progress in this field. I remain convinced that the task at hand is simply too large and complex for carmakers to handle on their own, and that progress will require shared, cross-industry or even transnational approaches. While new partnerships have emerged since BMW and Daimler abandoned their joint effort including Daimler and Nvidia, BMW and Intel/Mobileye, and Ford and VW - even these may not suffice because the mountain to be climbed is just too high. In his Report on Automotive Electronics (a feature in ATZelectronic since the first issue this year) from October 2019, Paul Hansen addressed the significant problems still to be solved in the detection of objects (for example pedestrians) for AEB, which is an important prerequisite for autonomous driving. A study report issued by the American Automobile Association in August 2020 also deals with the lack in detection reliability. These reports make clear that major technological and validation improvements will need to be made to enable the shift of responsibility to the vehicle control system - with no human intervention in critical situations.
Refining AEB systems, as well as a wide array of other complex autonomous systems, will require robust knowledge transfer. That's why an impressive panel of speakers will be addressing a host of key topics at our conference - ranging from evaluation procedures for virtual test driving to the securing of automated driving functions across entire vehicle lifecycles. The main focus is on examining the development of automated driving functions from cradle to grave while also providing visitors ample opportunities to exchange their ideas with others in the field.

The implementation of automated driving, or rather the many small steps to get there, will by far not be as trivial as many people would like it to be - and anything but an easy task. And who knows whether it is even feasible from an economical, safety or ethical point of view.

We hope you enjoy reading this latest issue!

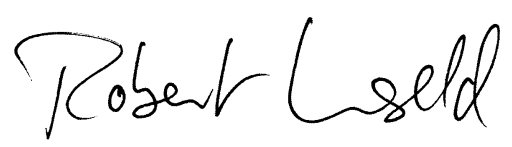

Robert Unseld

Responsible Editor

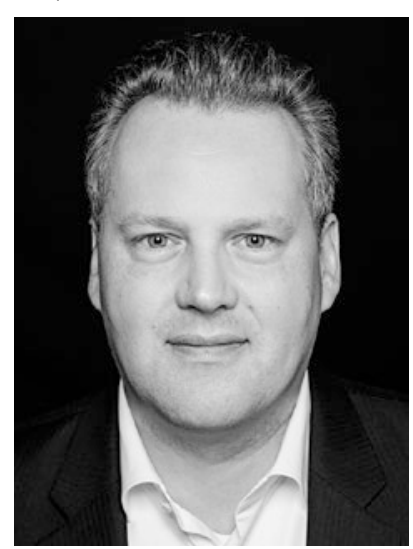

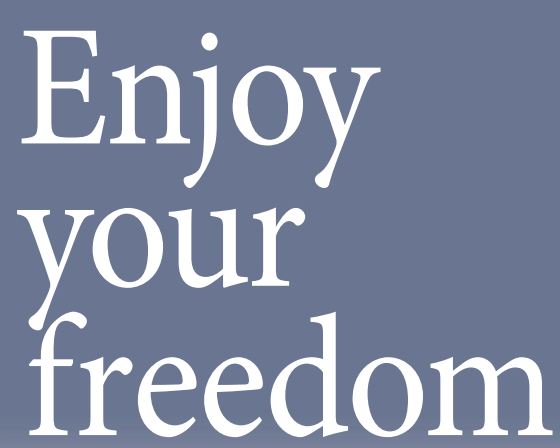

And still work in a secure, regulated environment?

Greater functionality and development times that barely give you chance to catch your breath. We respond to this complex challenge with efficient approaches to development, verification, and validation that we establish working shoulder to shoulder with industry and science. This way, we pave the way for you to transform ideas you're passionate about into innovative technologies. Let us bring out the best in you and your aspirations in the technical world.

ITK Engineering GmbH - Your reliable partner for system and software development.

www.itk-engineering.com

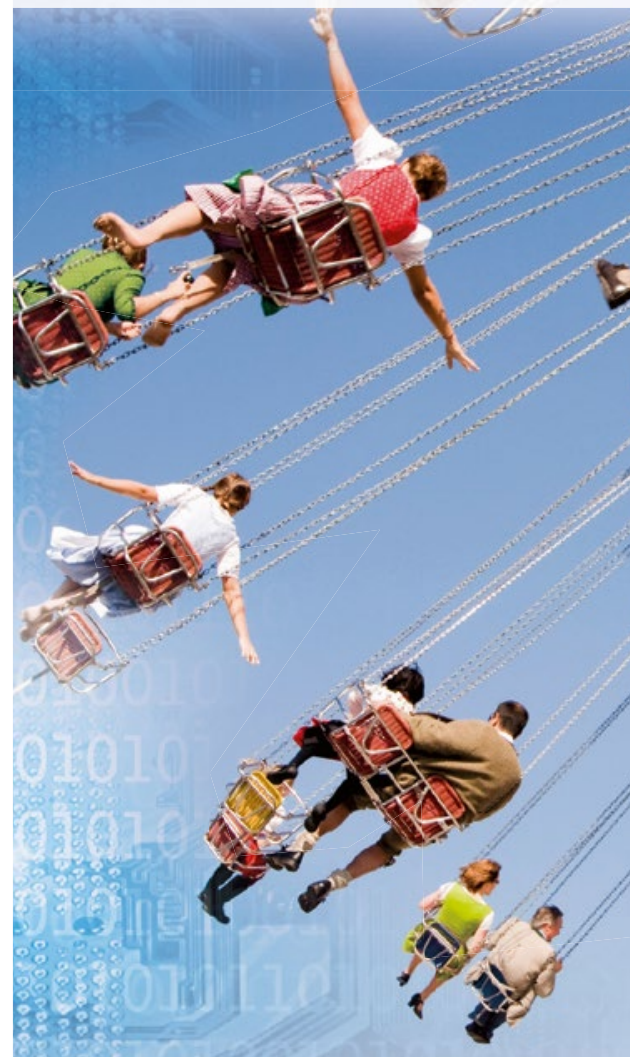

